\title{
Pitfalls to avoid when using phage display for snake toxins
}

Laustsen, Andreas Hougaard; Lauridsen, Line Præst; Lomonte, Bruno; Andersen, Mikael Rørdam; Lohse, Brian

Published in:

Toxicon

Link to article, DOI:

10.1016/j.toxicon.2016.12.010

Publication date:

2017

Document Version

Peer reviewed version

Link back to DTU Orbit

Citation (APA):

Laustsen, A. H., Lauridsen, L. P., Lomonte, B., Andersen, M. R., \& Lohse, B. (2017). Pitfalls to avoid when using phage display for snake toxins. Toxicon, 79-89. https://doi.org/10.1016/j.toxicon.2016.12.010

\section{General rights}

Copyright and moral rights for the publications made accessible in the public portal are retained by the authors and/or other copyright owners and it is a condition of accessing publications that users recognise and abide by the legal requirements associated with these rights.

- Users may download and print one copy of any publication from the public portal for the purpose of private study or research.

- You may not further distribute the material or use it for any profit-making activity or commercial gain

- You may freely distribute the URL identifying the publication in the public portal

If you believe that this document breaches copyright please contact us providing details, and we will remove access to the work immediately and investigate your claim. 


\section{Accepted Manuscript}

Pitfalls to avoid when using phage display for snake toxins

Andreas Hougaard Laustsen, Line Præst Lauridsen, Bruno Lomonte, Mikael Rørdam Andersen, Brian Lohse

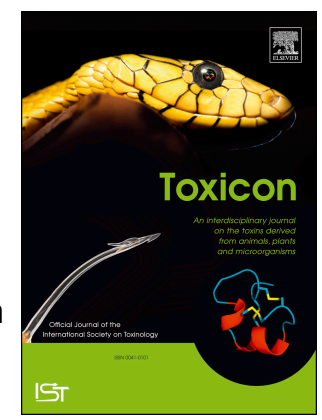

PII: S0041-0101(16)30630-4

DOI: $\quad$ 10.1016/j.toxicon.2016.12.010

Reference: TOXCON 5528

To appear in: Toxicon

Received Date: 7 November 2016

Revised Date: 12 December 2016

Accepted Date: 21 December 2016

Please cite this article as: Laustsen, A.H., Lauridsen, L.P., Lomonte, B., Andersen, M.R., Lohse, B., Pitfalls to avoid when using phage display for snake toxins, Toxicon (2017), doi: 10.1016/ j.toxicon.2016.12.010.

This is a PDF file of an unedited manuscript that has been accepted for publication. As a service to our customers we are providing this early version of the manuscript. The manuscript will undergo copyediting, typesetting, and review of the resulting proof before it is published in its final form. Please note that during the production process errors may be discovered which could affect the content, and all legal disclaimers that apply to the journal pertain. 


\section{Pitfalls to avoid when using phage display for snake toxins}

4

\author{
Andreas Hougaard Laustsen ${ }^{1,2}$, Line Præst Lauridsen ${ }^{1}$, Bruno Lomonte ${ }^{3}$, Mikael Rørdam \\ Andersen $^{1}$, Brian Lohse ${ }^{2}$ \\ ${ }^{1}$ Department of Biotechnology and Biomedicine, Technical University of Denmark, Denmark \\ ${ }^{2}$ Department of Drug Design and Pharmacology, Faculty of Health and Medical Sciences, \\ University of Copenhagen, Denmark \\ ${ }^{3}$ Instituto Clodomiro Picado, Facultad de Microbiología, Universidad de Costa Rica, \\ San José, Costa Rica
}

Running title: Pitfalls and solutions for phage display experiments

Keywords: Recombinant antivenom; next generation antivenom; phage display; biotinylation; antibody technology; amber codons; clone picking

\section{Address for correspondence:}

Dr. Brian Lohse

Associate Professor

Department of Drug Design and Pharmacology

Faculty of Health and Medical Sciences

University of Copenhagen

Denmark

bril@sund.ku.dk 
Abstract

33 Antivenoms against bites and stings from snakes, spiders, and scorpions are associated 34 with immunological side effects and high cost of production, since these therapies are still 35 derived from the serum of hyper-immunized production animals. Biotechnological 36 innovations within envenoming therapies are thus warranted, and phage display 37 technology may be a promising avenue for bringing antivenoms into the modern era of 38 biologics. Although phage display technology represents a robust and high-throughput 39 approach for the discovery of antibody-based antitoxins, several pitfalls may present 40 themselves when animal toxins are used as targets for phage display selection. Here, we 41 report selected critical challenges from our own phage display experiments associated 42 with biotinylation of antigens, clone picking, and the presence of amber codons within 43 antibody fragment structures in some phage display libraries. These challenges may be 44 detrimental to the outcome of phage display experiments, and we aim to help other 45 researchers avoiding these pitfalls by presenting their solutions. 


\section{Introduction}

Envenomings from snakes, scorpions, and spiders represent a serious neglected health issue in large parts of the developing world, causing pain and suffering to millions of victims with severe cases resulting in amputation (for snakebite) or even death (David Warrell et al., 2007; Williams et al., 2011). The cornerstone of envenoming therapies still consist of animal-derived antisera, which remain the only effective treatment options against snakebites, spider bites, and scorpion stings (Chippaux, 2012; Everardo Remi Rodríguez Rodríguez et al., 2015; Gutiérrez et al., 2011). However, since antisera suffer from drawbacks including immunogenicity due to their heterologous nature, complex production processes due to dependence on venoms and the immune systems of production animals, and batch-to-batch variation, an increasing amount of research is being focused on alternative approaches based on monoclonal antibodies and recombinant DNA technology (Laustsen et al., 2016a, 2016c; Richard et al., 2013; Rodríguez-Rodríguez et al., 2016; Roncolato et al., 2015). These novel approaches may hold the promise of delivering biotechnology-based therapies with improved efficacy, higher safety, and potentially lower cost of production (Laustsen et al., 2016a, 2016b; Rodríguez-Rodríguez et al., 2016).

One approach that has gained increasing attention within development of novel antivenoms is the use of phage display technology for discovery of antibodies and antibody fragments (Roncolato et al., 2015). Phage display technology exploits the linkage between antibody genotype and phenotype obtained by incorporating antibody genes, typically single-chain variable fragments (scFvs) or single-domain antibody fragments $\left(\mathrm{V}_{\mathrm{H}} \mathrm{Hs}\right.$ or Nanobodies $^{\circledR}$ ) (Figure 1) into the DNA of bacteriophages displaying the antibody peptide sequence on its outer coat (Laustsen, 2016a) (Figure 2). In addition to phage display technology, several other approaches for development of novel antivenoms and antitoxins have been investigated, such as the use of small molecules (Lewin et al., 2016), the use of 
technology (Castro et al., 2014; Frauches et al., 2013). However, it is beyond the scope of this article to discuss these approaches in detail (see (Laustsen et al., 2016a, 2016d; Roncolato et al., 2015) for comprehensive reviews of these topics).

In phage display experiments, the M13 bacteriophage is often employed to create a library, where antibody fragments are displayed on the pIII coat protein of the M13 phage virion, while the antibody fragment encoding gene is incorporated into the DNA of the phage virion (Hoogenboom et al., 1998; Rodi and Makowski, 1999; Sidhu, 2000), see Figure 2. The phage display library is then used for in vitro selection by attaching the target antigen to a plate well or bead, and panning the phage virions onto the target (Parmley and Smith, 1988). Non-binding phages are then washed away after sufficient incubation time, and binding phages can be eluted, amplified in E. coli TG1, and either subjected to additional rounds of panning or analysis (typically ELISA or gel electrophoresis). After a few cycles of panning, monoclonal phage virions can be isolated and their DNA sequenced in order to reveal the sequence of the displayed antibody fragment (Laustsen, 2016a). Several factors influence the outcome of a phage display experiment, including the introduction of deselection steps to remove unwanted antibody fragments, the affinity of the displayed antibody fragments, the level of antibody display, antigen immobilization and presentation, and clonal variation. Clonal variation may further affect antibody fragment translation, folding, transport, and stability of the fusion, which may further create amplification biases towards phage virions displaying undesired antibody fragments (Barbas et al., 1991; Bass et al., 1990; Garrard et al., 1991; John McCafferty, 1996; Lowman et al., 1991).

Since McCafferty et al. reported the development of the first scFv phage display library in 1990 (McCafferty et al., 1990), a wealth of antibodies and antibody fragments have successfully reached the clinic for a wide range of indications (Nelson and Reichert, 2009; Schofield et al., 2007). In the field of antivenom development, phage display technology 
was already introduced in 1995 when Meng et al. isolated the first murine scFv against different Mojave rattlesnake toxins (Meng et al., 1995). Since then, other researchers have reported the discovery of both human scFvs and camelid $\mathrm{V}_{\mathrm{H}} \mathrm{Hs}$ against phospholipases $\mathrm{A}_{2}$ and neurotoxins from both vipers and elapids (Chavanayarn et al., 2012; Kulkeaw et al., 2009; Richard et al., 2013; Roncolato et al., 2013; Stewart et al., 2007; Tamarozzi et al., 2006). Yet, antivenoms have still not entered the modern era of biopharmaceuticals, where protein-based therapies are produced recombinantly (Laustsen, 2016a; Laustsen et al., 2016a, 2016d). Part of the reason that this transition from serum-based therapies to recombinant antivenoms has not yet occurred is due to the difficulty of obtaining sufficient funding and resources for developing complex biologic therapies against conditions affecting mainly poor and rural communities of the tropical regions of the world. However, another part of the explanation could be the different technical obstacles encountered in phage display experiments, where animal venom toxins are used as targets. Many animal venom toxins are difficult to isolate in sufficient amounts and in high purity (Roncolato et al., 2015), the venoms may be difficult to procure, and the medically relevant venom components need to be identified (Laustsen et al., 2015c), which may be further complicated by toxin synergism (Laustsen, 2016b). In addition to some of the general considerations when using phage display technology, including loss of diversity during the panning and amplification rounds (Derda et al., 2011) and ineffective incorporation of the pIII-antibody protein (Roncolato et al., 2015), other specific challenges may be encountered in antitoxin discovery projects based on phage display.

In this paper, we report five non-obvious obstacles that we have encountered in our research within antitoxin phage display. These obstacles have significantly delayed our own research, and therefore we wish to help other researchers by discussing how they present themselves and their solutions. It should be noted that the results presented here are from our ongoing work on developing toxin-neutralizing antibodies and antibody fragments. 
125

126

127

128

129

130

131

132

133

134

135

Thus, our antibodies and antibody fragments are at the time of writing still undergoing preclinical evaluation. However, irrespectively of whether our efforts of developing toxin-neutralizing antibodies will be successful, the challenges and solutions presented here are universal in nature for the identification of toxin-binding and/or toxin-neutralizing antibody fragments. Although these obstacles and solutions presented here do not exhaustively cover all challenges that may be encountered in phage display experiments, it is the hope that they may help the growing number of researchers already engaged or about to engage in development of next generation antivenoms against snake, scorpion, spider, and bee envenomings. Additional tricks for optimizing phage display experiments exists.

These include switching of saturant (blocking buffer) between panning rounds, the use of chaotrophic agents during pannings, or performing pannings at low or elevated temperature to select for binder with thermostability (or to preserve antigens that are unstable at given temperatures). Other phage display challenges, including avidity, clonal variation, stability of the antigen, and the level of display, are discussed elsewhere (John McCafferty, 1996).

\section{Materials and Methods}

\subsection{Venoms and toxins}

Venom fractions containing Short neurotoxin 1, dendrotoxins, and $\alpha$-elapitoxins from the venom of D. polylepis were purified according to the protocol given in (Laustsen et al., 2015d). D. polylepis venom and purified $\alpha$-cobratoxin from $N$. kaouthia were obtained from Latoxan SAS, France. A. laevis venom was obtained from four specimens kept at the National Aquarium, Den Blå Planet, Denmark, frozen, lyophilized, and kept at $-20{ }^{\circ} \mathrm{C}$. $\mathrm{PLA}_{2} \mathrm{~S}$ were isolated according to a protocol similar to the one found in (Laustsen et al., 2015b). All toxins employed in the studies reported here were in a molecular range of 6 $\mathrm{kDa}$ to $14 \mathrm{kDa}$. 


\subsection{Biotinylation}

Different toxins from Naja kaouthia and Dendroaspis polylepis were dissolved in

152 phosphate buffered saline (PBS, Dulbecco's Phosphate Buffered Saline Sigma-Aldrich) to

153 yield concentration between 0.5 to $6 \mu \mathrm{g} / \mu \mathrm{l}$. Biotin linked to $N$-hydroxysuccinimide (NHS)

154 via two different linkers (Aliphatic linker: EZ-Link ${ }^{\mathrm{TM}}$ Sulfo-NHS-LC-Biotin, No-Weigh ${ }^{\mathrm{TM}}$

155 Format, 21327, Thermo Scientific. PEG 4 -linker: EZ-Link ${ }^{\mathrm{TM}}$ NHS-PEG -Biotin, $^{-}$

156 No-Weigh ${ }^{\mathrm{TM}}$ Format, 21329, Thermo Scientific) was added in toxin to biotinylation reagent

157 at ratios from 1:1.5 to $1: 20$ according to the protocol supplied by the manufacturer and left

158 at room temperature for $30 \mathrm{~min}$. Purification of the biotinylated toxins was achieved using

159 buffer exchange columns (Vivacon 500, Sartorius, 2000 Da Molecular Weight Cut-Off).

160 After three washes with $500 \mu \mathrm{L}$ PBS, the columns were turned and the biotinylated toxins

161 were eluted in 100-200 $\mu$ L PBS.

162 The extent of biotinylation of the toxins was assessed using a Pierce ${ }^{\mathrm{TM}}$ Fluorescence

163 Biotin Quantitation Kit (46610, Thermo Scientific), following the protocol supplied by the 164 manufacturer.

165 Protein concentrations were determined using absorbances measured on a BMG

166 labtech PHERAStar Fluorescence Spectrophotometer and individually calculated extinction 167 coefficients (http://web.expasy.org/protparam/).

\subsection{MS analysis}

Purified biotinylated toxins and native toxins were adsorbed onto C18 micro-ZipTips

170 (Millipore) to wash out any salt contaminants, after which the toxins were eluted with $2 \mathrm{uL}$

$17150 \%$ acetonitrile in water, containing $0.1 \%$ trifluoroacetic acid, directly onto an OptiTOF

172384 plate. Immediately following, the eluate was mixed with $0.6 \square \mathrm{L}$ matrix (saturated

$173 \alpha$-cyanohydroxycinnamic acid in 50\% acetonitrile, $0.1 \%$ TFA) and allowed to dry. The

174 samples were analyzed by MALDI-TOF in a Proteomics Analyzer 4800 Plus mass 
175

176

181

spectrometer (Applied Biosystems) operated in positive linear mode. Spectra were acquired using 1000 shots at a laser intensity of 4800 .

\subsection{Phage display selection protocol 1 (phospholipases $A_{2}$ from Aipysurus laevis)}

Three phage display selection rounds using Tomlinson I + J libraries were carried out as described in the following. MaxiSorp ${ }^{\mathrm{TM}}$ plates (NUNC, Roskilde, Denmark) were coated with $100 \mu 1$ of phospholipases $\mathrm{A}_{2}$, A. laevis crude venom, or streptavidin (Sigma-Aldrich, Saint Louis, USA) dissolved in PBS at a concentration of $0.01 \mu \mathrm{g} / \mu \mathrm{l}$ and left overnight at 4 ${ }^{\circ} \mathrm{C}$. Uncoated wells were left with PBS. The following day, wells with directly coated toxin were washed three times with PBS, filled to the brim with $2 \%$ milk powder (Fluka analytical) dissolved in PBS (2\% M-PBS), and incubated at room temperature for two hours in order to block the wells. Streptavidin-coated wells were blocked for one hour with 2\% M-PBS, after which $100 \mu$ l biotinylated toxin $(1 \mu \mathrm{g})$ dissolved in $2 \%$ M-PBS was added and left for one hour to bind. After blocking and binding of biotinylated toxin, all wells were washed three times with PBS and approximately $10^{13}$ phages dissolved in $100 \mu \mathrm{l}$ $2 \%$ M-PBS of library I and J respectively were added and incubated for one hour at room temperature with shaking $(250 \mathrm{rpm})$, followed by one hour of incubation at room temperature without shaking. Supernatant was discarded and the plates were washed ten times with PBS containing 0.1\% Tween ${ }^{\circledR} 20$ (PBST, Sigma-Aldrich). Phages were eluted by adding $100 \mu \mathrm{l}$ per well of trypsin-PBS (diluted 1:5 in PBS, Sigma-Aldrich). Supernatant was transferred to an Eppendorf tube containing $600 \mu 1$ of E. coli TG1 grown in 2xTY to an $\mathrm{OD}_{600}=0.4$ and was incubated at $37{ }^{\circ} \mathrm{C}$ for 30 minutes without shaking. The cells were then spun down at 11,600 x $\mathrm{g}$ for five minutes, resuspended in $50 \mu 12 \mathrm{xTY}$, and plated out on TYE-agar (containing $100 \mu \mathrm{g} / \mathrm{ml}$ ampicillin and $1 \%$ glucose). All plates were incubated (bottom up) overnight at $37^{\circ} \mathrm{C}$. 
The following day, $2 \mathrm{ml}$ 2xTY was added to the overnight grown plates and the cells

were loosened with a spreader. From these solutions, $10 \mu \mathrm{l}$ was transferred to $10 \mathrm{ml}$ fresh

$2 \mathrm{xTY}$ containing $100 \mu \mathrm{g} / \mathrm{ml}$ ampicillin and $1 \%$ glucose and incubated until $\mathrm{OD}_{600}=0.4$ was reached (approx. 1 hour). Following this, $5 \times 10^{10}$ helper phage in $100 \mu$ l was added to the $10 \mathrm{ml}$ and incubated at $37{ }^{\circ} \mathrm{C}$ without shaking for 30 minutes. The culture was spun down at 3,000 x g (Sigma Centrifuge 4K15) for ten minutes and the pellet resuspended in $25 \mathrm{ml}$ of 2 XTY containing $100 \mu \mathrm{g} / \mathrm{ml}$ ampicillin, $50 \mu \mathrm{g} / \mathrm{ml}$ kanamycin, and $0.1 \%$ glucose, and incubated overnight at $30{ }^{\circ} \mathrm{C}$. The following day, the overnight culture was spun down at 3,300 x g for 15 minutes. Then, $6.25 \mathrm{ml} \mathrm{PEG/NaCl}$ (20\% Polyethylene glycol 6000, $2.5 \mathrm{M}$ $\mathrm{NaCl}$ ) was mixed well with supernatant and left on ice for one hour. This solution was then spun at 3,300 x $\mathrm{g}$ for $30 \mathrm{~min}$, the $\mathrm{PEG} / \mathrm{NaCl}$ was discarded, and the pellet resuspended in 2 $\mathrm{ml}$ PBS. The resuspended pellet was spun at $11,600 \times \mathrm{g}$ for ten minutes (to remove cellular debris) and $1 \mathrm{ml}$ of the phage containing supernatant was transferred to a new $1.5 \mathrm{ml}$ 212 microcentrifuge tube. Two more rounds of selection were performed according to the 213 procedure described above.

214 Isolation of monoclonal binders was achieved by plating out individual E. coli TG1 215 colonies on TYE-agar plates. Colonies from these plates were transferred using an 216 inoculation loop into $100 \mu \mathrm{l} 2 \mathrm{xTY}$ containing $100 \mu \mathrm{g} / \mathrm{ml}$ ampicillin and $1 \%$ glucose in 96 217 well plates and grown shaking overnight at $37^{\circ} \mathrm{C}$. The following day, $20 \mu 1$ was transferred 218 from the overnight plates to a second 96 well plate containing $200 \mu 1$ of 2 xTY with 100 $219 \mu \mathrm{g} / \mathrm{ml}$ ampicillin and $1 \%$ glucose. These were grown for one hour at $37{ }^{\circ} \mathrm{C}$. Then $25 \mu \mathrm{l}$ $2202 \mathrm{xTY}$ containing $100 \mu \mathrm{g} / \mathrm{ml}$ ampicillin, $1 \%$ glucose, and $10^{9}$ helper phage was added to 221 each well. The plate was incubated another hour at $37{ }^{\circ} \mathrm{C}$, while shaking. Afterwards, the 222 plate was centrifuged for ten $\min$ at $1,800 \mathrm{x} \mathrm{g}$ and the supernatant was aspirated off. The 223 pellet was resuspended in $200 \mu \mathrm{l} 2 \mathrm{xTY}$ containing $100 \mu \mathrm{g} / \mathrm{ml}$ ampicillin and $50 \mu \mathrm{g} / \mathrm{ml}$ kanamycin and grown overnight shaking at $30{ }^{\circ} \mathrm{C}$. The following day, overnight cultures 
were spun down at $1,800 \mathrm{x}$ g for ten minutes and $50 \mu \mathrm{l}$ of the supernatant was mixed with $50 \mu 14 \%$ M-PBS and used in monoclonal phage ELISA as described in section 2.6.

227

\subsection{Phage display selection protocol 2 ( $\alpha$-cobratoxin from Naja kaouthia)}

Vials (NUNC, Immuno Tube MaxiSorp, PK3000) were coated with $250 \mu \mathrm{L} 10 \mu \mathrm{g} / \mathrm{mL}$ streptavidin (Pierce ${ }^{\circledR}$ Streptavidin, 21125, Thermo Scientific) in PBS and left at $4{ }^{\circ} \mathrm{C}$ overnight. $100 \mathrm{~mL}$ of $2 \mathrm{xYT}$ media was inoculated with E. coli TG1 and incubated at 250 rpm and $37^{\circ} \mathrm{C}$ overnight.

Next day, the vials were washed three times with $4 \mathrm{~mL}$ PBS and blocked with $4 \mathrm{~mL}$ $3 \%$ milk in PBS (M-PBS) for 1 hour at room temperature. Meanwhile, $420 \mu \mathrm{L}$ of IONTAS phage library (an updated version of the library developed by Schofield et al. (Schofield et al., 2007)) was mixed with $420 \mu \mathrm{L} 6 \%$ M-PBS and $840 \mu \mathrm{L} 3 \%$ M-PBS and incubated for 1 hour at room temperature to pre-block the library. Simultaneously, $420 \mu \mathrm{L}$ of Dynabeads M-280 Streptavidin (10 mg/mL, 11206D, Invitrogen by Life Technologies) was washed three times with $800 \mu \mathrm{L} \mathrm{3 \%} \mathrm{M-PBS} \mathrm{and} \mathrm{re-suspended} \mathrm{in} 1 \mathrm{~mL}$ 3\% M-PBS and incubated for 1 hour on a rotor. After one hour of blocking with M-PBS, $250 \mu \mathrm{L}$ of $5 \square \mathrm{g} / \mathrm{ml}$ biotinylated toxin (Dp4, Dp5, Dp6, Dp7, Dp8, and Dp20 from D. polylepis and $\alpha$-cobratoxin (and $\alpha$-Cbtx) from Naja kaouthia) in 3\% M-PBS was added to the vials. The vials were then incubated at room temperature for 1 hour. The Dynabeads M-280 Streptavidin centrifuged at 15,000 rpm for $5 \mathrm{~min}$, the supernatant removed, and the beads were re-dissolved in $420 \mu \mathrm{L} \mathrm{3 \%}$ M-PBS. The beads were then mixed with the pre-blocked library and incubated for 1 hour at room temperature on a rotor. Meanwhile, an appropriate amount (determined by OD measurement) of the overnight TG1 culture was added to a shake flask containing $100 \mathrm{~mL} 2 \mathrm{xYT}$ and set to grow at $37^{\circ} \mathrm{C}$ at $250 \mathrm{rpm}$ for $1-2$ hours. After 1 hour on rotor, the phage library was separated from the beads by 1 min centrifugation at 15,000 rpm (Eppendorf Centrifuge 5417R), followed by placing the 
250 Eppendorf tube on a magnetic rack, and using a pipette. The vials were washed five times

251 with $\mathrm{PBS}$, and $250 \mu \mathrm{L}$ of the separated phage solution was added to the vials, which were

252 then incubated at room temperature for 1 hour. The vials containing the phages were 253 washed six times with $4 \mathrm{~mL}$ PBS $+0.2 \%$ Tween $^{\circledR} 20$ and six times with $4 \mathrm{~mL}$ PBS. Then, $254250 \mu \mathrm{L}$ of trypsin in Phage Elution Buffer (1/100 dilution of TPCK-trypsin from $10 \mu \mathrm{g} / \mathrm{mL}$ 255 stock in $50 \mathrm{mM}$ Tris $\mathrm{pH} 8,1 \mathrm{mM} \mathrm{CaCl}_{2}$ ) was added to the vials, and the vials were 256 incubated at room temperature for $15 \mathrm{~min}$. The solutions from the vials were added to 257 Falcon tubes containing $5 \mathrm{~mL}$ TG1 culture with an $\mathrm{OD}_{600}$ of 0.5 , which were incubated at $25837{ }^{\circ} \mathrm{C}$ at $150 \mathrm{rpm}$ for 1 hour. After incubation, $10 \mu \mathrm{L}$ of the cultures were added to 259 Eppendort tubes containing $990 \mu \mathrm{L} 2 \mathrm{xYT}$. After mixing, two 2xYT-AG (2xYT containing $2602 \%$ glucose and $100 \mu \mathrm{g} / \mathrm{mL}$ ampicillin) plates were prepared for each culture by adding 10 $261 \mu \mathrm{L}$ of the solutions and $100 \mu \mathrm{L}$ of the solutions, respectively to each plate. The plates were 262 incubated at $30{ }^{\circ} \mathrm{C}$ overnight and counted next day to determine cfu. The remaining 263 solutions in the Falcon tubes were centrifuged for $10 \mathrm{~min}$ at $2100 \mathrm{~g}$ (Heraus Megafuge 40R 264 Centrifuge). The supernatants were discarded, and the pellets were re-suspended in $50 \mu \mathrm{L}$ 2652 xYT and plated out on an 2xYT-AG plate. The plates (termed Output plates) were 266 incubated at $30{ }^{\circ} \mathrm{C}$ overnight. As controls, $200 \mu \mathrm{L}$ of the TG1 culture was also plated out on 267 both a 2 XYT-AG plate and a 2 XYT-KG plate $(2 x Y T$ containing $2 \%$ glucose and $50 \mu \mathrm{g} / \mathrm{mL}$ 268 kanamycin). The $2 \mathrm{xYT}-\mathrm{AG}$ plate was incubated at $30{ }^{\circ} \mathrm{C}$ overnight. The $2 \mathrm{xYT}-\mathrm{KG}$ plate 269 was incubated at $37^{\circ} \mathrm{C}$ overnight.

270 Next day, the Output plates were scraped using $2 \mathrm{~mL}$ of a solution containing: $14 \mathrm{~mL}$ 271 of 2 XYT, $6 \mathrm{~mL}$ of $50 \%$ glycerol, and $100 \mu \mathrm{g} / \mathrm{ml}$ ampicillin. The $2 \mathrm{~mL}$ were transferred to $27250 \mathrm{~mL}$ Falcon tubes and rotated for $30 \mathrm{~min}$. A sufficient amount (determined by $\mathrm{OD}_{600}$ ) of 273 the Output scraping was used to inoculate $10 \mathrm{~mL}$ of $2 \mathrm{xYT}-\mathrm{AG}$ to obtain an $\mathrm{OD}_{600}$ of 0.1 . 274 These new suspensions were incubated at $37{ }^{\circ} \mathrm{C}$ at $250 \mathrm{rpm}$ for 1.5 hours. The remaining of 275 the Output scrapings were stored in cryo tubes at $-80{ }^{\circ} \mathrm{C}$. Once the incubated solutions had 
reached an $\mathrm{OD}_{600}$ of $0.4-0.5,100 \mu \mathrm{L}$ of MK13KO7-trp helper phages (1/3000 dilution of 6

277

278

x 1014 phage/mL in 2 XYT-AG) was added, and the solutions were incubated at $37{ }^{\circ} \mathrm{C}$ at $150 \mathrm{rpm}$ for 1 hour. After 1 hour, the cells were centrifuged for $10 \mathrm{~min}$ at $2100 \mathrm{~g}$. The supernatants were removed by decanting. The cells were re-suspended in Erlenmeyer flasks containing $40 \mathrm{~mL}$ of 2 XYT-AK $(2 x Y T$ containing $100 \mu \mathrm{g} / \mathrm{mL}$ of Ampicillin and $50 \mu \mathrm{g} / \mathrm{mL}$ of Kanamycin) and incubated at $25^{\circ} \mathrm{C}$ at $280 \mathrm{rpm}$ overnight.

Next day, the different solutions incubated in Erlenmeyer flasks were transferred to Falcon tubes and spun down at 10,500 g for $10 \mathrm{~min}$ (Sorvall Lynx 4000 Centrifuge). The supernatants were transferred to $50 \mathrm{~mL}$ Falcon tubes containing $10 \mathrm{~mL}$ 20\% PEG-8000 + 2.5 $\mathrm{M} \mathrm{NaCl}$, mixed, and kept on ice for 1 hour to allow precipitation. After 1 hour, the phages were centrifuged at $15,000 \mathrm{~g}$ for $10 \mathrm{~min}$ (Sorvall Lynx 4000 Centrifuge). The supernatants were discarded, and the phage pellets were re-suspended in $500 \mu \mathrm{L}$ PBS in Eppendorf tubes. The Eppendorf tubes were centrifuged at 9,300 g for $10 \mathrm{~min}$ (Eppendorf Centrifuge 5417R), and the supernatants were transferred to other Eppendorf tubes to get rid of cell debris. This was done twice more, since cell debris continued to be present.

Two more rounds of selection were performed according to the procedure described above with two exceptions: 1) In round 2 and 3, the phage libraries were not pre-incubated with Dynabeads M-280 Streptavidin. 2) Instead of streptavidin, $10 \mu \mathrm{g} / \mathrm{mL}$ NeutrAvidin (NeutrAvidin $^{\mathrm{TM}}$ Biotin Binding Protein, 31000, Thermo Scientific) was used for coating in round 2 to deselect the streptavidin-binding phages.

\subsection{ELISA protocol 1}

Polyclonal phage binders to the toxins, obtained from the Tomlinson $\mathrm{I}+\mathrm{J}$ libraries after each of the rounds of selection, were investigated using ELISA. First, a MaxiSorp ${ }^{\mathrm{TM}}$ plate was coated with toxins or streptavidin overnight as described in section 2.5. The following day, wells coated with toxin were washed three times with PBS, filled to the brim 
with $2 \% \mathrm{M}-\mathrm{PBS}$, and incubated at room temperature for two hours to block the wells.

302 Streptavidin-coated wells were blocked for one hour with 2\% M-PBS, after which $100 \mu 1$ 303 biotinylated toxin $(1 \mu \mathrm{g})$ dissolved in 2\% M-PBS was added, and the well was left for one

304 hour to allow biotin capture. Each well was then washed three times with PBST and two 305 times with PBS to remove unspecific binders. Then, a mixture of $50 \mu 14 \%$ M-PBS and 50 $306 \mu$ phage from each panning round was added to their respective wells and incubated for 307 one hour on a plate shaker. Wells were then washed three times with PBS and two times 308 with PBST, and $100 \mu \mathrm{l}$ of solution containing a 1:1000 dilution of anti-M13 monoclonal 309 antibody (Horseradish Peroxidase conjugated, GE Healthcare) in 2\% M-PBS was added to 310 each well and incubated at one hour at room temperature on a plate shaker. Wells were 311 washed three times with PBST and two times with PBS. Then $100 \mu$ of OPD solution (2 312 mg ortho-Phenylenediamine, DAKO, and $2.5 \mu \mathrm{L} \mathrm{H}_{2} \mathrm{O}_{2}$ in $2.5 \mathrm{ml} \mathrm{H} \mathrm{H}_{2} \mathrm{O}$ ) was added to each 313 well to achieve color development. Reactions were stopped by adding $100 \mu 10.5 \mathrm{M} \mathrm{H}_{2} \mathrm{SO}_{4}$ 314 (Sigma-Aldrich) to each well and absorbances were measured at $490 \mathrm{~nm}$ (VersaMax 315 Tunable Microplate reader, Molecular Devices).

\subsection{ELISA protocol 2}

The progress of the panning rounds in Phage Display Experiment 2 was monitored by ELISA. Each panning round was tested against the following antigens: Dp4, Dp5, Dp6,

Dp7, Dp8, and $\alpha$-cobratoxin, and synthesized epitopes (Epitope 1, 2, and 3) representing

320 linear epitopes from type 1 and type $2 \alpha$-neurotoxins from $D$. polylepis (Laustsen, 2016a).

Wells (NUNC, MaxiSorp) were coated with $100 \mu \mathrm{L} 10 \mu \mathrm{g} / \mathrm{mL}$ streptavidin (Pierce $^{\circledR}$

322 Streptavidin, 21125, Thermo Scientific) in PBS and left at $4 \mathrm{C}$ overnight. Control wells 323 were coated with $10 \mu \mathrm{g} / \mathrm{mL}$ NeutrAvidin (NeutrAvidinn ${ }^{\mathrm{TM}}$ Biotin Binding Protein, 31000, 324 Thermo Scientific). 
Next day, the wells were washed three times with PBS and blocked with $200 \mu \mathrm{L} 2 \%$

326 M-PBS for 1 hour at room temperature on a mixer. The wells were then washed three times with PBS. $50 \mu \mathrm{l}$ of $1 \mu \mathrm{g} / \mathrm{ml}$ of all different antigens and $50 \mu \mathrm{L}$ of $10 \mu \mathrm{g} / \mathrm{ml}$ for selected peptides (Epitope 1, Epitope 2, Epitope 3) in 2\% M-PBS was added to their respective wells, and the plates were incubated for 2.5 hours at room temperature on a mixer. The first control wells (NeutrAvidin) were left in or $200 \mu \mathrm{L}$ of $2 \%$ M-PBS, while the second control wells (streptavidin) wells were left in $50 \mu \mathrm{l}$ of $2 \%$ M-PBS on a mixer. The wells were washed three times with PBS. Solutions of $50 \mu$ of the different 50x phage libraries (dilution $1 / 100$ in $2 \% \mathrm{M}-\mathrm{PBS}$ ) found during selections rounds were added to their respective wells in duplicates. The wells were put on mixer for 1 hour. The wells were washed three times with PBS $+0.2 \%$ Tween $^{\circledR} 20$ and three times with PBS. $50 \mu \mathrm{L}$ of Mouse anti-M13 antibody (GE Healthcare) in 2\% M-PBS (dilution 1/1000) was added to each well. The wells were put on mixer for 1 hour, followed by three washes with PBS + $0.2 \%$ Tween $^{\circledR} 20$ and three times with PBS. $100 \mu \mathrm{L}$ of Europium labeled anti-mouse antibody (Perkin Elmers) in 2\% M-PBS (dilution 1/1000) was added to each well. The wells were put on mixer for 1 hour, washed three times with PBS $+0.2 \%$ Tween $^{\circledR} 20$ and three times with PBS. $100 \mu \mathrm{L}$ of DELFIA enhancement solution was added to each well. The wells were put on mixer for 5 minutes. The plates were read using a BMG labtech PHERAStar Fluorescence Spectrophotometer (excitation 340 nm, emission 615 nm).

\section{Results and discussion}

The pitfalls presented here were encountered during the course of approximately 50 different phage display selection experiments against snake venom toxins involving different displayed peptide, $\mathrm{V}_{\mathrm{H}} \mathrm{H}$, and human $\mathrm{scFv}$ phage display libraries. From these, the results presented here will utilize six illustrative experiments with human $\mathrm{scFv}$ 
350 libraries, of which four were run in parallel against phospholipases $A_{2}$ from the olive

351 sea snake, Aipysurus laevis, according to section 2.4 in Materials and Methods, and

352 two were run in sequence against $\alpha$-cobratoxin, the medically most important toxin

353 from the monocled cobra, Naja kaouthia (Laustsen et al., 2015a), according to section

$354 \quad 2.5$ in Materials and Methods.

\subsection{Optimal display of antigens via biotinylation}

Biotinylation of antigens involves the covalent attachment of a biotin molecule to the antigen via a chemical linker. Biotinylation may be employed for obtaining a better display of the antigen, as the linker will enable the antigen to be distanced from the solid-phase surface, when streptavidin coated wells, beads, or vials are used for panning, thereby avoiding conformational change of the antigen and reducing the possibility of steric hindrance in the antigen-antibody interaction. Although biotinylation may thus provide beneficial properties to a phage display selection experiment, this extra step may also bring about experimental complications, of which some will be discussed in the following.

\subsubsection{Biotinylation versus direct coating}

An important advantage of immobilization of biotinylated antigens to streptavidin via a linker in comparison with directly coated antigens is that the antigen may be better presented. This may allow for a larger part of its surface to interact with phage virions during pannings (Bronfman et al., 2003) and the achievement of better control of the concentration of bound antigen. Immobilization via a linker also allows the antigen to be distanced from the bottom and inner walls of the well, vial, or surface of a bead. This may contribute to better preservation of the native conformation of the antigen, which may in some cases be denatured when directly coated (see Figure 4A and 4B). However, the drawbacks of biotinylation include the addition of an extra (antigen consuming) step in the 
374 discovery process and the possibility that biotinylation may interfere with a desired site on

375 the antigen, which would have been optimal for selection.

376 In our experiments, we compared the outcomes from panning rounds with the

377 Tomlinson I and J libraries (human scFv libraries) against both biotinylated $\mathrm{PLA}_{2} \mathrm{~s}$ captured

378 by streptavidin (see Figure $5 \mathrm{~A}$ and $5 \mathrm{~B}$ ) and directly coated $\mathrm{PLA}_{2}$ s from A. laevis (see

379 Figure 5C and 5D). No normalization of the phage concentrations between different

380 panning rounds was performed. Therefore the polyclonal ELISA results should mainly be

381 used to evaluate signal ratios for a given panning round between target toxin and control.

382 Based on the high signal intensities and signal ratios in ELISA assays between these

383 different panning rounds, our results indicate that much better selection is obtained for the

384 biotinylated $\mathrm{PLA}_{2} \mathrm{~S}$ than for the un-biotinylated $\mathrm{PLA}_{2} \mathrm{~S}$, possibly due to better antigen

385 presentation. Furthermore, when comparing the selectivity of polyclonal phage virions it is

386 seen from the binding signals that phage virions from the Tomlinson I library selected

387 against biotinylated $\mathrm{PLA}_{2} \mathrm{~S}$ were specific towards the biotinylated $\mathrm{PLA}_{2} \mathrm{~S}$ and did not bind

388 to directly immobilized $\mathrm{PLA}_{2} \mathrm{~S}$ after the third round of panning (Figure 6A). In contrast,

389 phage virions from the Tomlinson $\mathrm{J}$ library selected against biotinylated $\mathrm{PLA}_{2} \mathrm{~s}$ bind to both

390 biotinylated $\mathrm{PLA}_{2} \mathrm{~S}$ and native $\mathrm{PLA}_{2} \mathrm{~S}$ (Figure 6B, panning round 3). The quality (e.g.

391 diversity in displayed antibody fragments, naivety, and size) of a phage display antibody

392 library is of high importance for the outcome of a phage display experiment. This is

393 supported by the results presented in Figure 5 and Figure 6, from which it could be inferred

394 that the Tomlinson Library I is of lower quality than the Tomlinson Library $\mathbf{J}$ in this given

395 experiment, since selective PLA $_{2}$ binders are more quickly accumulated from this library.

396 Nevertheless, it is seen in Figure 6A that a large decrease in signal intensities in the ELISA

397 occur for the Tomlinson Library I between the second and third round of panning,

398 indicating that successful positive selection of selective binder against biotinylated PLA 2 has occurred. 
Our results thus suggest that immobilization of $\mathrm{PLA}_{2} \mathrm{~S}$ via biotinylation and

401 streptavidin capture may provide better selection conditions for discovery of 402 toxin-binding scFvs via phage display. As an alternative solution, other researchers

403 have successfully employed amine binding plates for antigen immobilization via direct 404 chemical coupling of toxins to the bottom of the wells (through a spacer) for the 405 discovery of camelid $\mathrm{V}_{\mathrm{H}} \mathrm{H}$ inhibitors of $\alpha$-cobratoxin (Richard et al., 2013). Outside of 406 toxinology, immobilization to streptavidin-coated beads has successfully been used to 407 identify scFv binders via solution-based panning (see e.g. (Haque and Tonks, 2012)), 408 however, since these approaches have not been employed to discover antitoxins, they 409 will not be discussed further here, but may be worth exploring for the interested 410 researcher.

\subsubsection{Over-biotinylation of antigen}

Although biotinylation of the antigen may provide better selection condition during a

413 phage display experiment, it is of paramount importance that the antigen is optimally

414 biotinylated (one biotin per antigen for small toxins). Over-biotinylation may lead to masking of the antigen itself, thereby hindering the phage virions from accessing it (Figure 4C). In experiments performed with the IONTAS human scFv library (an updated version

417 of the library developed by Schofield et al. (Schofield et al., 2007)) using $\alpha$-cobratoxin as 418 the antigen, two different batches of biotinylated $\alpha$-cobratoxin were employed. In the first 419 batch, $\alpha$-cobratoxin had been biotinylated at a toxin-to-biotinylation reagent-ratio of 1:20 420 (leading to over-biotinylation, see Figure 7). In the second batch, $\alpha$-cobratoxin had been 421 biotinylated at a toxin-to-biotinylation reagent-ratio of 1:1.5 (primarily leading to singly biotinylated antigen). The extent of biotinylation was originally assessed using the Pierce $\mathrm{T}^{\mathrm{TM}}$

423 Fluorescence Biotin Quantitation Kit (46610, Thermo Scientific), according to which $424 \alpha$-cobratoxin molecules had been biotinylated 0.7 times on average. However, when 
assessed by MS (see Figure 7) it was evident that an average of 3-4 biotin moieties (each moiety having a mass of $0.5 \mathrm{kDa}$ ) had been conjugated to the antigen. This difficulty of over-biotinylation was unfortunately not immediately uncovered. Therefore, initial phage display selection experiments were performed, which did not yield polyclonal phage binders (Figure 8A). When the second batch of singly biotinylated $\alpha$-cobratoxin was used, selection rounds yielded a good pool of $\alpha$-cobratoxin binders that showed cross-recognition to homologous type $2 \alpha$-neurotoxins present in fractions Dp6 and Dp7 from D. polylepis venom (Figure 8B).

Again, our results demonstrate the applicability of the biotinylation approach for snake toxins to be used as antigens in phage display selection experiments, but also underline the importance of obtaining an optimal biotin-to-toxin ratio.

\subsubsection{The effect of linker physico-chemistry}

Many snake toxins have a small mass (three-finger toxins: 6-8 kDa and PLA 2 : $12-14$ $\mathrm{kDa}$ ), and since the biotinylation of a protein adds an additional $0.5 \mathrm{kDa}$ to the molecule, the nature of the linker may have a profound effect on the physico-chemical properties of the antigen. Two different linkers were assessed in the biotinylation of different toxins (Aliphatic linker: EZ-Link ${ }^{\mathrm{TM}}$ Sulfo-NHS-LC-Biotin, No-Weigh ${ }^{\mathrm{TM}}$ Format, 21327, Thermo Scientific. PEG 4 -linker: EZ-Link ${ }^{\mathrm{TM}}$ NHS-PEG 4 -Biotin, No-Weigh ${ }^{\mathrm{TM}}$ Format, 21329, Thermo Scientific). In several experiments performed using the aliphatic linker, a white precipitate was clearly observed. In contrast, when using a hydrophilic $\mathrm{PEG}_{4}$-linker, no precipitate could be seen, and NanoDrop ${ }^{\circledR}$ measurements of protein concentration in the purified solutions of toxins biotinylated with the $\mathrm{PEG}_{4}$-linker confirmed that the biotinylated toxins were still in solution. It is therefore suggested that the hydrophobic nature of the aliphatic linker has a detrimental effect on the hydrophobicity of the biotinylated toxins leading to precipitation (Figure 9A). Thus, the use of more hydrophilic 
450 linkers, such as the $\mathrm{PEG}_{4}$-linker, may indeed be favorable for small snake toxins, as it

451 allows the toxins to remain in solution (Figure 9B).

452 Additionally, the length of the linker may have an impact on antigen presentation, and

453 it may occasionally be worthwhile to test different linker lengths to identify one that 454 provides better display of the antigen. Taken together with the fact that streptavidin may 455 bind up to four different biotin moieties, using biotinylation and streptavidin capture could 456 at least theoretically lead to crowding of the presented toxins. This may potentially have 457 negative effects on phage display selection experiments, as this may render entire or parts 458 of the presented toxin antigen unavailable for binding interaction.

\subsection{Clone picking}

In phage display selection experiments performed with the Tomlinson I and J libraries

on biotinylated $\mathrm{PLA}_{2} \mathrm{~S}$ from A. laevis, polyclonal ELISAs revealed that an accumulation of

$\mathrm{PLA}_{2}$-specific phage virions had taken place in the course of the three panning rounds

(Figure 5A and 5B). From the different panning rounds (particularly round 2 and 3) phage virions were used to transfect $E$. coli TG1 cells, which were plated out to yield monoclonal TG1 colonies. Two different screening experiments were then performed on selected colonies. In the first experiment 288 primarily large colonies were picked and screened by monoclonal ELISA. This yielded a low rate of positive PLA2-binders $(3.8 \%$ of clones

469 showing a signal three times higher than the background signal), see Figure 10A. Due to 470 the somewhat unsuccessful outcome of this experiment, another 84 primarily small colonies 471 were picked from the same plates and screened by monoclonal ELISA. In contrast, this 472 yielded a high percentage of positive, selective PLA $_{2}$-binders $(54.8 \%$ of clones showing a 473 signal three times higher than the background signal), see Figure 10B. This observation is 474 likely to be explained by the fact that phage production may be proportional to colony size. 
475 Phage virions with truncations in (or absence of) their displayed antibody fragment create

476 less metabolic strain on their host cells. These host cells therefore have a growth advantage

477 in comparison to cells infected by phage virions displaying fully functional high affinity

478 scFvs (Bruin et al., 1999). Clones with a growth advantage multiply faster, allowing them

479 to produce more phage virions, since more phage virion producing cells will be present and

480 since each phage virion is produced with less metabolic cost. Therefore, such "non-antigen

481 binding" phage virions will dominate the total pool of phage virions despite having a lower

482 affinity to the antigen target (Umlauf et al., 2015). Also, antibody fragments that are toxic

483 to bacteria may be deleted due to negative selection pressure during amplification

484 (Schofield et al., 2007). Thus, supported by observations reported in the scientific literature,

485 our results indicate that an undesired growth bias may interfere with isolation of high 486 affinity toxin binders in phage display experiments. This growth bias may however to some 487 extent be dealt with by careful selection of small colonies over larger ones.

\subsection{Amber codons in antibody libraries}

A final pitfall that may be encountered when using certain libraries (such as the 491 Tomlinson libraries) in phage display selection experiments is the presence of amber codons within the scFv fragment. Amber codons (TAG) are typically stop codons, which may however by some organisms and strains (such as the E. coli TG1 strain, which is a non-suppressor of the amber codon) be interpreted as a codon for glutamate. The amber codon is intentionally inserted after the myc-tag (see Figure 11) in e.g. the Tomlinson libraries, which allows for full biosynthesis of the scFv-pIII product in TG1 cells, but which will terminate protein synthesis in prior to gIII in non-suppressor strains (such as E. coli

498 HB2151). This allows for easy expression of soluble scFvs following infection of a non-suppressor strain with phages directly after a phage display selection experiment. The 
pitfall with amber codons, however, presents itself, when an amber codon is present within

501 the scFv fragment - a phenomenon occurring due to the approaches used for construction

502 of certain libraries (such as the Tomlinson library). When this occurs, the functional

503 scFv-pIII product may be obtained from the TG1 strain and thus be enriched by phage

504 display selection, but the construct will be prematurely terminated, when the soluble scFv expression is attempted in other strains. The presence of amber codons resulting in premature termination of protein synthesis has been reported by $\mathrm{Wu}$ et al. (Wu et al., 2007) and Roncolato et al. (Roncolato et al., 2015). In our phage display selection experiments against $\mathrm{PLA}_{2} \mathrm{~S}$ from A. laevis, we encountered the amber codon in the CDR2 region of the $\mathrm{V}_{\mathrm{H}}$ of some of our scFv binders (Figure 11). In order to overcome this pitfall, it is a necessity to sequence the phagemid DNA and either introduce a glutamate encoding codon

511 instead of the premature amber codon by site directed mutagenesis (Barderas et al., 2006),

512 or simply to synthesize the entire scFv gene construct and transform it into the expression 513 strain. This can be a cumbersome process, and undetected, it can lead to large amounts of 514 wasted time.

\section{Concluding remarks}

The pitfalls presented here do not comprise an exhaustive set of challenges that may be encountered during phage display selection experiments with the purpose of identifying

519 toxin-binding scFvs for the development of recombinant antivenoms. However, they do provide further insight into certain difficulties revolving around proper presentation of toxin antigens, how to avoid growth bias and select bacterial colonies expressing high affinity binder, and how to detect and possibly circumvent the difficulty that premature amber codons present in the $\mathrm{scFv}$ gene sequence represent. It is the hope that these findings may help to guide researchers in their efforts towards developing recombinant antivenoms 
526 such efforts may ultimately help envenomed victims in poor rural parts of the world, where 527 most envenomings occur.

528

529 
References

Barbas, C.F., Kang, A.S., Lerner, R.A., Benkovic, S.J., 1991. Assembly of combinatorial antibody libraries on phage surfaces: the gene III site. Proc. Natl. Acad. Sci. U. S. A. 88, 7978-7982.

Barderas, R., Shochat, S., Martínez-Torrecuadrada, J., Altschuh, D., Meloen, R., Ignacio Casal, J., 2006. A fast mutagenesis procedure to recover soluble and functional scFvs containing amber stop codons from synthetic and semisynthetic antibody libraries. J. Immunol. Methods 312, 182-189. doi:10.1016/j.jim.2006.03.005

Bass, S., Greene, R., Wells, J.A., 1990. Hormone phage: an enrichment method for variant proteins with altered binding properties. Proteins 8, 309-314. doi:10.1002/prot.340080405

Bronfman, F.C., Tcherpakov, M., Jovin, T.M., Fainzilber, M., 2003. Ligand-induced internalization of the p75 neurotrophin receptor: a slow route to the signaling endosome. J. Neurosci. Off. J. Soc. Neurosci. 23, 3209-3220.

Bruin, R. de, Spelt, K., Mol, J., Koes, R., Quattrocchio, F., 1999. Selection of high-affinity phage antibodies from phage display libraries. Nat. Biotechnol. 17, 397-399. doi:10.1038/7959

Castro, J.M.A., Oliveira, T.S., Silveira, C.R.F., Caporrino, M.C., Rodriguez, D., Moura-da-Silva, A.M., Ramos, O.H.P., Rucavado, A., Gutiérrez, J.M., Magalhães, G.S., Faquim-Mauro, E.L., Fernandes, I., 2014. A neutralizing recombinant single chain antibody, scFv, against BaP1, A P-I hemorrhagic metalloproteinase from Bothrops asper snake venom. Toxicon Off. J. Int. Soc. Toxinology 87, 81-91. doi:10.1016/j.toxicon.2014.05.017

Chavanayarn, C., Thanongsaksrikul, J., Thueng-in, K., Bangphoomi, K., Sookrung, N., Chaicumpa, W., 2012. Humanized-Single Domain Antibodies (VH/VHH) that Bound Specifically to Naja kaouthia Phospholipase A2 and Neutralized the Enzymatic Activity. Toxins 4, 554-567. doi:10.3390/toxins4070554

Chippaux, J.-P., 2012. Emerging options for the management of scorpion stings. Drug Des. Devel. Ther. 6, 165-173. doi:10.2147/DDDT.S24754

David Warrell, José María Gutiérrez, A. Padilla, 2007. Rabies and Envenomings: a Neglected Public Health Issue: Report of a Consultative Meeting. World Health Organization, Geneva.

Derda, R., Tang, S.K.Y., Li, S.C., Ng, S., Matochko, W., Jafari, M.R., 2011. Diversity of phage-displayed libraries of peptides during panning and amplification. Mol. Basel Switz. 16, 1776-1803. doi:10.3390/molecules16021776

Everardo Remi Rodríguez Rodríguez, Lidia Riaño Umbarila, Lourival D. Possani, Baltazar Becerril, 2015. Recombinant Neutralizing Antibodies, A New Generation of Antivenoms, in: Toxinology - Scorpion Venoms. Springer, Dordrecht Heidelberg New York London, p. 580.

Frauches, T.S., Petretski, J.H., Arnholdt, A.C.V., Lasunskaia, E.B., de Carvalho, E.C.Q., Kipnis, T.L., da Silva, W.D., Kanashiro, M.M., 2013. Bothropic antivenom based 
on monoclonal antibodies, is it possible? Toxicon 71, 49-56. doi:10.1016/j.toxicon.2013.05.005

Garrard, L.J., Yang, M., O’Connell, M.P., Kelley, R.F., Henner, D.J., 1991. Fab assembly and enrichment in a monovalent phage display system. Biotechnol. Nat. Publ. Co. 9, 1373-1377.

Gutiérrez, J.M., León, G., Lomonte, B., Angulo, Y., 2011. Antivenoms for snakebite envenomings. Inflamm. Allergy Drug Targets 10, 369-380.

Haque, A., Tonks, N.K., 2012. Use of Phage Display to Generate Conformation-Sensor Recombinant Antibodies. Nat. Protoc. 7, 2127-2143. doi:10.1038/nprot.2012.132

Harrison, R.., 2004. Development of venom toxin-specific antibodies by DNA immunisation: rationale and strategies to improve therapy of viper envenoming. Vaccine 22, 1648-1655. doi:10.1016/j.vaccine.2003.09.046

Hoogenboom, H.R., de Bruïne, A.P., Hufton, S.E., Hoet, R.M., Arends, J.-W., Roovers, R.C., 1998. Antibody phage display technology and its applications. Immunotechnology 4, 1-20. doi:10.1016/S1380-2933(98)00007-4

John McCafferty, 1996. Phage display: factors affecting panning efficiency. Phage Display of Peptides and Proteins: A Laboratory Manual, in: Phage Display of Peptides and Proteins. Academic Press Inc., San Diego, CA, USA, pp. 261-76.

Kulkeaw, K., Sakolvaree, Y., Srimanote, P., Tongtawe, P., Maneewatch, S., Sookrung, N., Tungtrongchitr, A., Tapchaisri, P., Kurazono, H., Chaicumpa, W., 2009. Human monoclonal ScFv neutralize lethal Thai cobra, Naja kaouthia, neurotoxin. J. Proteomics 72, 270-282. doi:10.1016/j.jprot.2008.12.007

Laustsen, A.H., 2016a. Recombinant antivenoms, 1st ed. University of Copenhagen, Copenhagen, Denmark.

Laustsen, A.H., 2016b. Toxin synergism in snake venoms. Toxin Rev. 35, 165-170. doi:10.1080/15569543.2016.1220397

Laustsen, A.H., Engmark, M., Milbo, C., Johannesen, J., Lomonte, B., Gutiérrez, J.M., Lohse, B., 2016a. From Fangs to Pharmacology: The Future of Snakebite Envenoming Therapy. Curr. Pharm. Des. 22.

Laustsen, A.H., Gutiérrez, J.M., Lohse, B., Rasmussen, A.R., Fernández, J., Milbo, C., Lomonte, B., 2015a. Snake venomics of monocled cobra (Naja kaouthia) and investigation of human IgG response against venom toxins. Toxicon 99, 23-35. doi:10.1016/j.toxicon.2015.03.001

Laustsen, A.H., Gutiérrez, J.M., Rasmussen, A.R., Engmark, M., Gravlund, P., Sanders, K.L., Lohse, B., Lomonte, B., 2015b. Danger in the reef: Proteome, toxicity, and neutralization of the venom of the olive sea snake, Aipysurus laevis. Toxicon, Omic perspectives of the toxin universe 107, Part B, 187-196. doi:10.1016/j.toxicon.2015.07.008

Laustsen, A.H., Johansen, K.H., Engmark, M., Andersen, M.R., 2016b. Snakebites: costing recombinant antivenoms. Nature 538, 41. doi:10.1038/538041e

Laustsen, A.H., Lohse, B., Lomonte, B., Engmark, M., Gutiérrez, J.M., 2015c. Selecting key toxins for focused development of elapid snake antivenoms and inhibitors guided by a Toxicity Score. Toxicon 104, 43-45. doi:10.1016/j.toxicon.2015.07.334 
Laustsen, A.H., Lomonte, B., Lohse, B., Fernández, J., Gutiérrez, J.M., 2015d. Unveiling the nature of black mamba (Dendroaspis polylepis) venom through venomics and antivenom immunoprofiling: Identification of key toxin targets for antivenom development. J. Proteomics 119, 126-142. doi:10.1016/j.jprot.2015.02.002

Laustsen, A.H., Solà, M., Jappe, E.C., Oscoz, S., Lauridsen, L.P., Engmark, M., 2016c. Biotechnological Trends in Spider and Scorpion Antivenom Development. Toxins 8, 226. doi:10.3390/toxins8080226

Laustsen, A.H., Solà, M., Jappe, E.C., Oscoz, S., Lauridsen, L.P., Engmark, M., 2016d. Biotechnological trends in spider and scorpion antivenom development. Toxins Accepted.

Lewin, M., Samuel, S., Merkel, J., Bickler, P., 2016. Varespladib (LY315920) Appears to Be a Potent, Broad-Spectrum, Inhibitor of Snake Venom Phospholipase A2 and a Possible Pre-Referral Treatment for Envenomation. Toxins 8. doi:10.3390/toxins 8090248

Lowman, H.B., Bass, S.H., Simpson, N., Wells, J.A., 1991. Selecting high-affinity binding proteins by monovalent phage display. Biochemistry (Mosc.) 30, 10832-10838.

McCafferty, J., Griffiths, A.D., Winter, G., Chiswell, D.J., 1990. Phage antibodies: filamentous phage displaying antibody variable domains. Nature 348, 552-554. doi:10.1038/348552a0

Meng, J., John, T.R., Kaiser, I.I., 1995. Specificity and binding affinity of an anti-crotoxin combinatorial antibody selected from a phage-displayed library. Biochem. Pharmacol. 50, 1969-1977.

Nelson, A.L., Reichert, J.M., 2009. Development trends for therapeutic antibody fragments. Nat. Biotechnol. 27, 331-337. doi:10.1038/nbt0409-331

Parmley, S.F., Smith, G.P., 1988. Antibody-selectable filamentous fd phage vectors: affinity purification of target genes. Gene 73, 305-318. doi:10.1016/0378-1119(88)90495-7

Richard, G., Meyers, A.J., McLean, M.D., Arbabi-Ghahroudi, M., MacKenzie, R., Hall, J.C., 2013. In Vivo Neutralization of $\alpha$-Cobratoxin with High-Affinity Llama Single-Domain Antibodies (VHHs) and a VHH-Fc Antibody. PLoS ONE 8, e69495. doi:10.1371/journal.pone.0069495

Rodi, D.J., Makowski, L., 1999. Phage-display technology - finding a needle in a vast molecular haystack. Curr. Opin. Biotechnol. 10, 87-93. doi:10.1016/S0958-1669(99)80016-0

Rodríguez-Rodríguez, E.R., Olamendi-Portugal, T., Serrano-Posada, H., Arredondo-López, J.N., Gómez-Ramírez, I., Fernández-Taboada, G., Possani, L.D., Anguiano-Vega, G.A., Riaño-Umbarila, L., Becerril, B., 2016. Broadening the neutralizing capacity of a family of antibody fragments against different toxins from Mexican scorpions. Toxicon 119, 52-63. doi:10.1016/j.toxicon.2016.05.011

Roncolato, E.C., Campos, L.B., Pessenda, G., Costa e Silva, L., Furtado, G.P., Barbosa, J.E., 2015. Phage display as a novel promising antivenom therapy: A review. Toxicon 93, 79-84. doi:10.1016/j.toxicon.2014.11.001 
656

657

658

659

660

661

662

663

664

665

666

667

668

669

670

671

672

673

674

675

676

677

678

679

680

681

682

683

684

685

686

687

688

689

690

691

692

Roncolato, E.C., Pucca, M.B., Funayama, J.C., Bertolini, T.B., Campos, L.B., Barbosa, J.E., 2013. Human antibody fragments specific for Bothrops jararacussu venom reduce the toxicity of other Bothrops sp. venoms. J. Immunotoxicol. 10, 160-168. doi:10.3109/1547691X.2012.703253

Schofield, D.J., Pope, A.R., Clementel, V., Buckell, J., Chapple, S.D., Clarke, K.F., Conquer, J.S., Crofts, A.M., Crowther, S.R., Dyson, M.R., Flack, G., Griffin, G.J., Hooks, Y., Howat, W.J., Kolb-Kokocinski, A., Kunze, S., Martin, C.D., Maslen, G.L., Mitchell, J.N., O’Sullivan, M., Perera, R.L., Roake, W., Shadbolt, S.P., Vincent, K.J., Warford, A., Wilson, W.E., Xie, J., Young, J.L., McCafferty, J., 2007. Application of phage display to high throughput antibody generation and characterization. Genome Biol. 8, R254. doi:10.1186/gb-2007-8-11-r254

Sidhu, S.S., 2000. Phage display in pharmaceutical biotechnology. Curr. Opin. Biotechnol. 11, 610-616. doi:10.1016/S0958-1669(00)00152-X

Stewart, C.S., MacKenzie, C.R., Hall, J.C., 2007. Isolation, characterization and pentamerization of alpha-cobrotoxin specific single-domain antibodies from a naïve phage display library: preliminary findings for antivenom development. Toxicon Off. J. Int. Soc. Toxinology 49, 699-709. doi:10.1016/j.toxicon.2006.11.023

Tamarozzi, M.B., Soares, S.G., Marcussi, S., Giglio, J.R., Barbosa, J.E., 2006. Expression of recombinant human antibody fragments capable of inhibiting the phospholipase and myotoxic activities of Bothrops jararacussu venom. Biochim. Biophys. Acta 1760, 1450-1457. doi:10.1016/j.bbagen.2006.04.008

Umlauf, B.J., McGuire, M.J., Brown, K.C., 2015. Introduction of plasmid encoding for rare tRNAs reduces amplification bias in phage display biopanning. BioTechniques 58, 81-84. doi:10.2144/000114256

Wagstaff, S.C., Laing, G.D., Theakston, R.D.G., Papaspyridis, C., Harrison, R.A., others, 2006. Bioinformatics and multiepitope DNA immunization to design rational snake antivenom. PLoS Med 3, e184.

Williams, D.J., Gutiérrez, J.-M., Calvete, J.J., Wüster, W., Ratanabanangkoon, K., Paiva, O., Brown, N.I., Casewell, N.R., Harrison, R.A., Rowley, P.D., O’Shea, M., Jensen, S.D., Winkel, K.D., Warrell, D.A., 2011. Ending the drought: New strategies for improving the flow of affordable, effective antivenoms in Asia and Africa. J. Proteomics, "Omic" studies on Neglected Tropical Diseases 74, 1735-1767. doi:10.1016/j.jprot.2011.05.027

Wu, S., Ke, A., Doudna, J.A., 2007. A fast and efficient procedure to produce scFvs specific for large macromolecular complexes. J. Immunol. Methods 318, 95-101. doi:10.1016/j.jim.2006.10.005 
694

695

696

697

698

699

700

701

702

703

704

705

706

707

708

709

710

711

712

713

\section{Figure legends}

Figure 1. Overview of the different antibody formats employed to construct phage display antibody libraries and how these formats relate to human (scFv) and camelid $\left(\mathrm{V}_{\mathrm{H}} \mathrm{H}\right)$ antibodies, respectively.

Figure 2. Schematic representation of the M13 bacteriophage containing single-stranded DNA (ssDNA) and displaying an scFv on the pIII protein.

Figure 3. Schematic representation of a phage display selection experiment. (1) First the $\mathrm{scFv}$ displaying phage library is panned against the target toxin, which is bound to a well. (2) Non-binding phage particles are washed away. (3) Binding phage particles are eluted. (4) Phage particles are amplified and either submitted to another round of selection or (5) analyzed by polyclonal ELISA.

Figure 4. Schematic representation of antigen coating strategies and problems during phage display selection. (A) When an antigen is coated directly onto the bottom of a well (or surface of a bead), the antigen may change its native conformation. (B) Biotinylation of the antigen may provide a way to distance the antigen from the solid-phase surface and into solution for better accessibility and to avoid conformational change of the antigen. (C) Over-biotinylation of antigens can lead to masking of the antigen epitopes, hampering their recognition by antibody paratopes. 
717 Figure 5. Polyclonal ELISA results from Phage Display Experiment 1 with the

718 Tomlinson Libraries I and $\mathrm{J}$ against $\mathrm{PLA}_{2} \mathrm{~S}$ from A. laevis and control (uncoated) (see

719 Materials and Methods 2.4). (A) Tomlinson Library I panned against biotinylated PLA 2

720 toxins. (B) Tomlinson Library $\mathrm{J}$ panned against biotinylated PLA 2 toxins. (C)

721 Tomlinson Library I panned against directly coated $\mathrm{PLA}_{2}$ toxins. (D) Tomlinson

722 Library J panned against directly coated PLA 2 toxins.

724 Figure 6. Polyclonal ELISA results from Phage Display Experiment 1 with the

725 Tomlinson Libraries I and $\mathrm{J}$ against biotinylated $\mathrm{PLA}_{2} \mathrm{~S}$ and directly coated $\mathrm{PLA}_{2} \mathrm{~S}$ from

726 the A. laevis, streptavidin, and control (uncoated) (A) Tomlinson Library I. (B)

727 Tomlinson Library J.

729 Figure 7. MALDI-TOF mass spectra for $\alpha$-cobratoxin from Naja kaouthia biotinylated

730 with different toxin-to-biotinylation reagent-ratios showing that over-biotinylation

731 (more than one biotin moiety per toxin molecule) occurs at higher

732 toxin-to-biotinylation reagent-ratios. (A) Native $\alpha$-cobratoxin. (B) Biotinylated

$733 \alpha$-cobratoxin, toxin-to-biotinylation reagent-ratio: 1:1. (C) Biotinylated $\alpha$-cobratoxin,

734 toxin-to-biotinylation reagent-ratio: 1:2. (D) Biotinylated $\alpha$-cobratoxin,

735 toxin-to-biotinylation reagent-ratio: 1:5 (over-biotinylation). (E) Biotinylated

$736 \alpha$-cobratoxin, toxin-to-biotinylation reagent-ratio: 1:10 (over-biotinylation). (F)

$737 \quad$ Biotinylated $\quad \alpha$-cobratoxin, $\quad$ toxin-to-biotinylation $\quad$ reagent-ratio: $\quad 1: 20$

738 (over-biotinylation). 
Figure 8. Polyclonal phage ELISA for panning rounds 2 and 3 for the IONTAS scFv

741 phage display library panned against $\alpha$-cobratoxin from Naja kaouthia following Phage

742 display selection protocol 2 (see Materials and Methods 2.5). (A) ELISA results from

743 panning rounds using over-biotinylated $\alpha$-cobratoxin (toxin-to-biotinylation

744 reagent-ratio of 1:20). (B) ELISA results from panning rounds using $\alpha$-cobratoxin with

745 more optimal biotinylation (toxin-to-biotinylation reagent-ratio of 1:1.5). Dp5-Dp8:

746 Fractions 5, 6, 7, and 8 from Dendroaspis polylepis containing Short neurotoxin 1,

747 dendrotoxins, and $\alpha$-elapitoxins (numbering according to (Laustsen et al., 2015d)).

748 Cbtx: $\alpha$-cobratoxin from N. kaouthia.

Figure 9. Schematic representation of the effect of linker chemistry on the biotinylated antigen/toxin employed for phage display selection. (A) The solubility of small toxins may be highly affected by aliphatic linkers, which can lead to precipitation of the biotinylated antigen, making it useless for coating. (B) Using hydrophilic linkers (such as PEG-linkers) may retain the solubility of the toxin, thereby providing better antigens

755 for coating.

Figure 10. Monoclonal ELISA results for clones selected from various panning rounds in Phage Display Experiment 1 (see Materials and Methods 2.4). (A) In the first attempt, 288 clones were picked from primarily large colonies, of which only a very low number displayed binding to PLA 2 . (B) In the second attempt, 84 clones were

761 picked from small colonies, of which more than $50 \%$ displayed selective binding to PLA $_{2}$. Note: Clones were ranked and numbered according to their signal intensities. 
764 Figure 11. Conceptual sequence of one of our scFvs displaying the different elements

765 of the $\mathrm{scFv}$, the presence of a desired amber codon after the myc-tag, and an undesired

766 amber codon in the CDR2 region of the $\mathrm{V}_{\mathrm{H}}$.

767 
768 Figure 1

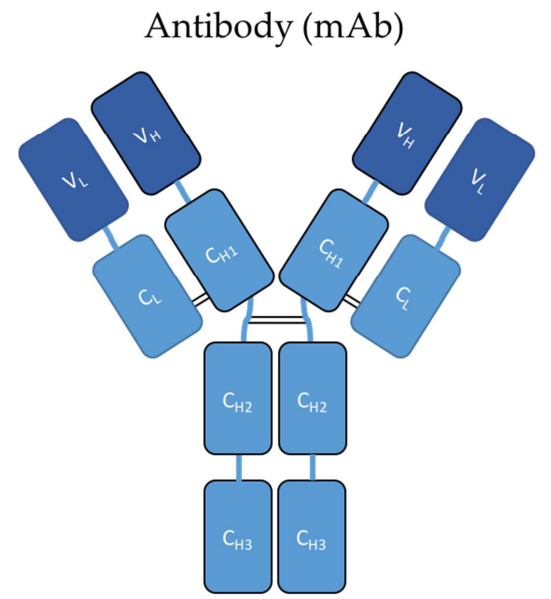

Used in Phage Display

Heavy chain antibody

769
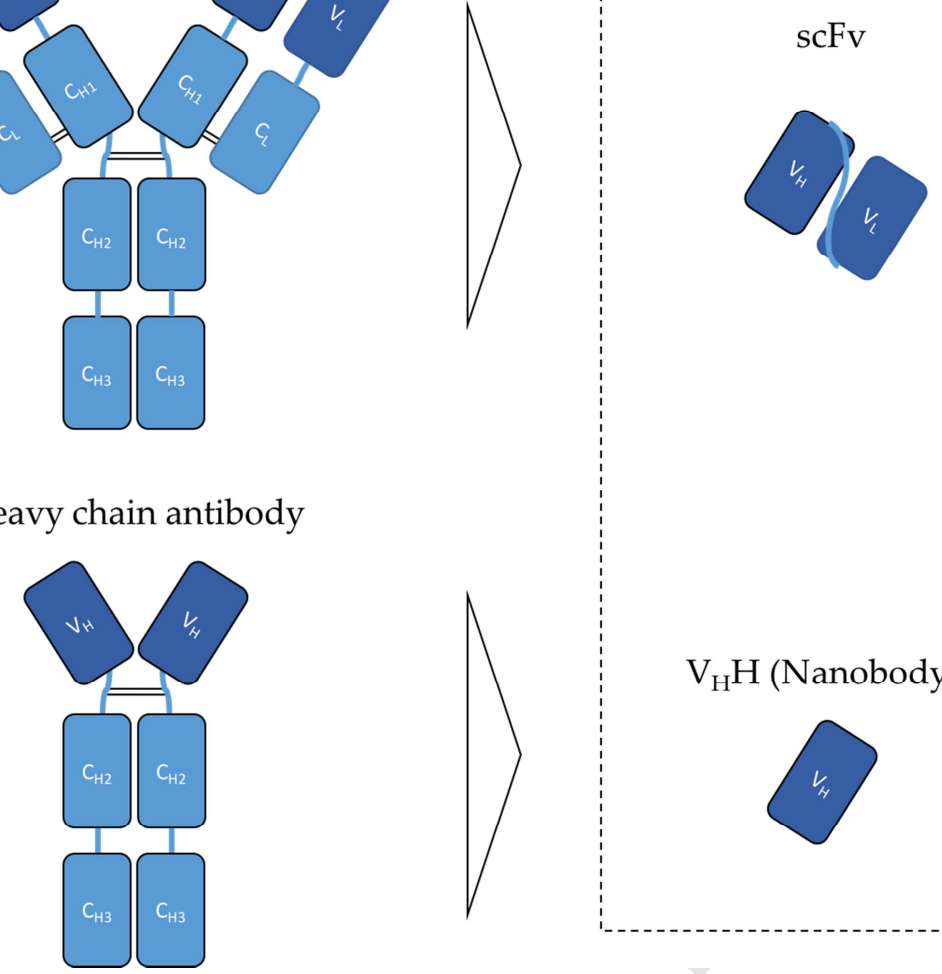

$\mathrm{V}_{\mathrm{H}} \mathrm{H}($ Nanobody®)

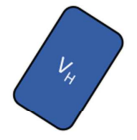


771 Figure 2

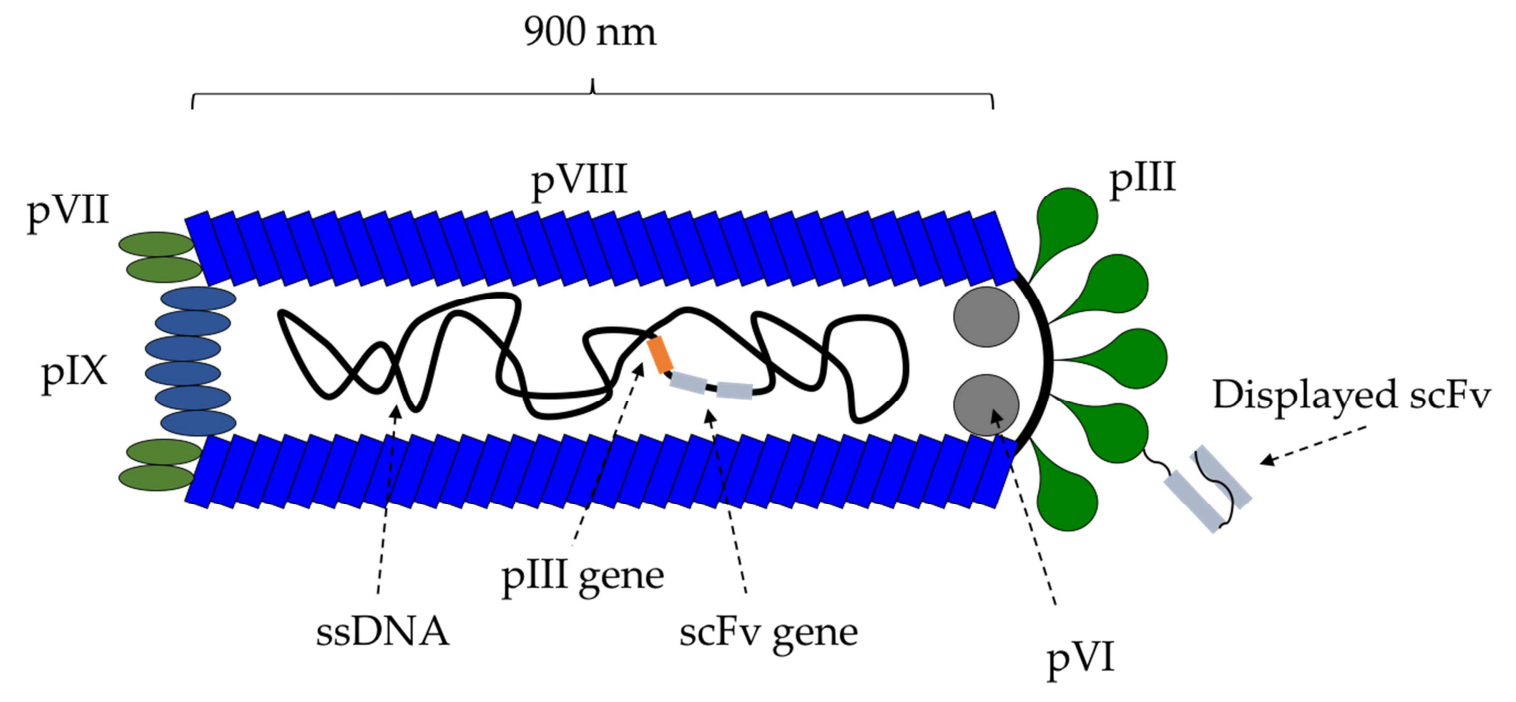

773 
$774 \quad$ Figure 3

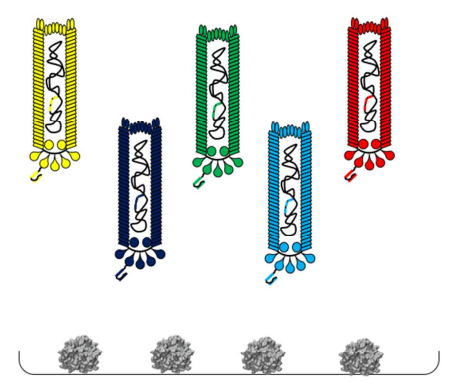

1. Panning

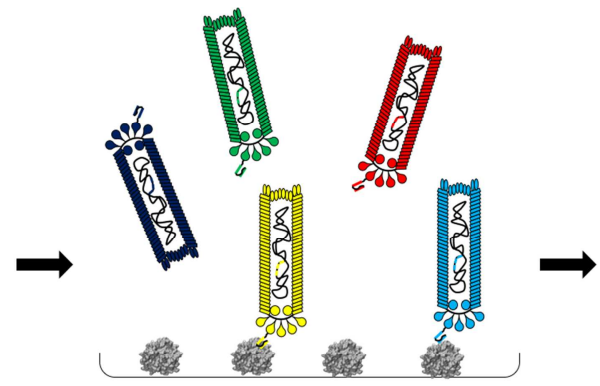

2. Binding \epeat

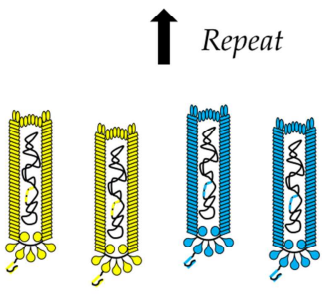

5. Amplification

$\begin{array}{llllll}0 & 0 & 0 & 0 & 0 & 0 \\ 0 & 0 & 0 & 0 & 0 & 0 \\ 0 & 0 & 0 & 0 & 0 & 0 \\ 0 & 0 & 0 & 0 & 0 & 0\end{array}$

6. ELISA

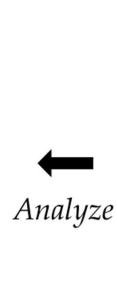

775

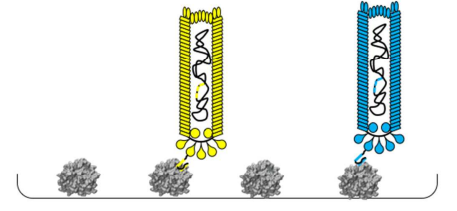

3. Washing

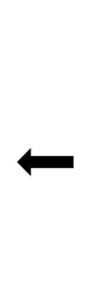

I

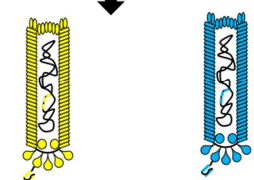

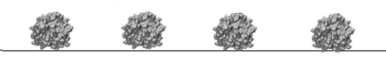

4. Elution 
$777 \quad$ Figure 4
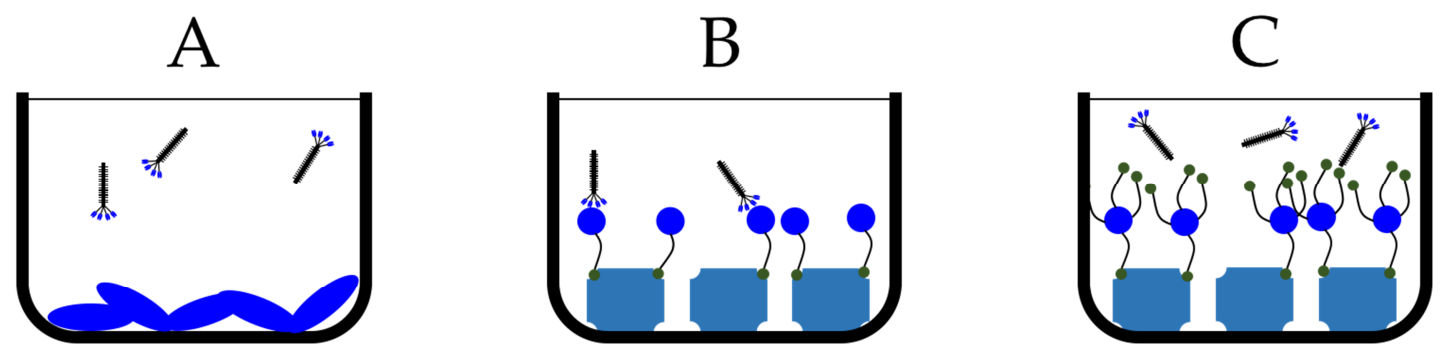

- Antigen

\. Phage

? Biotinylated antigen

778

Denatured antigen

Streptavidin

Over-biotinylated antigen 
$779 \quad$ Figure 5
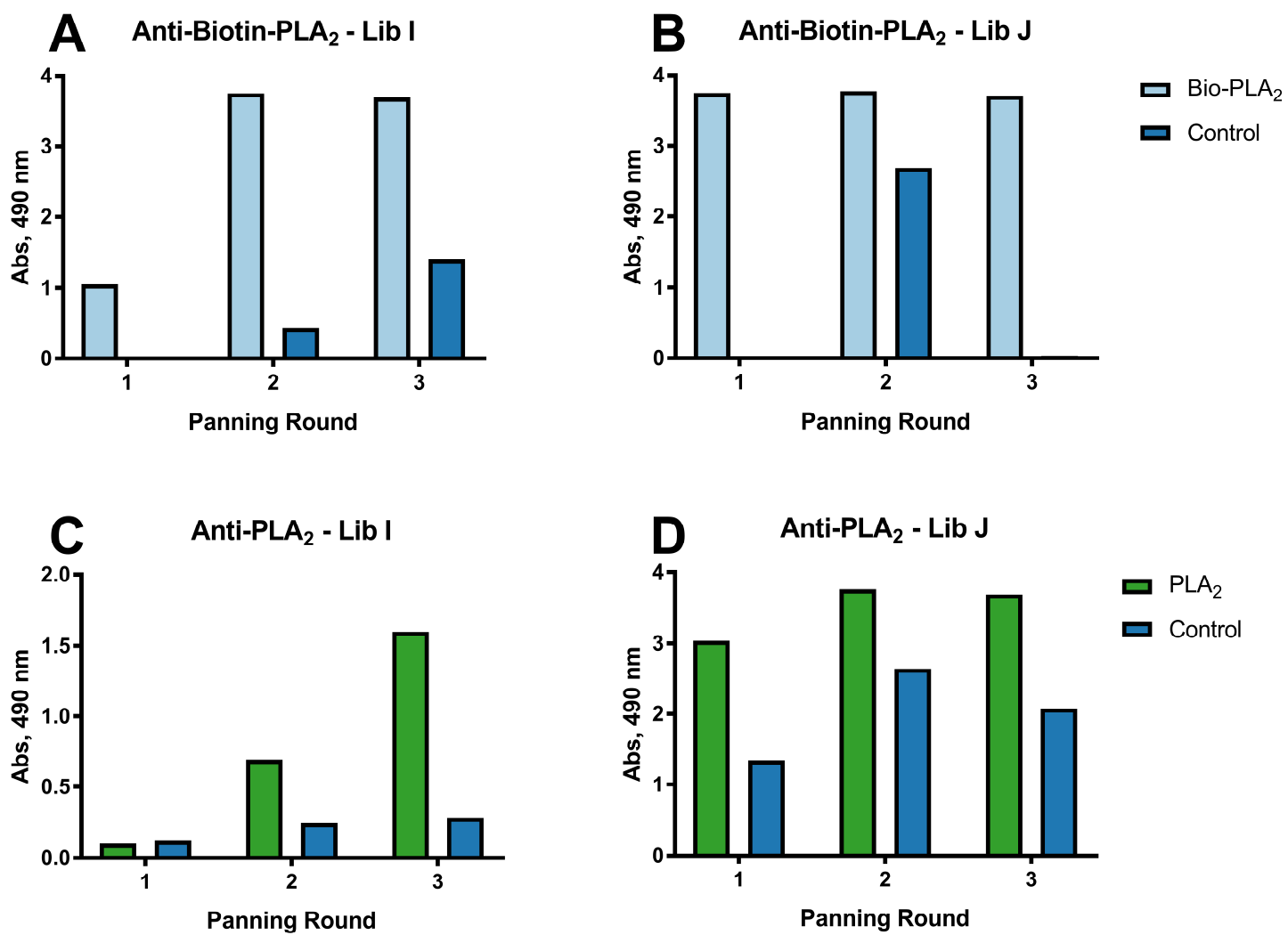

780 
Figure 6
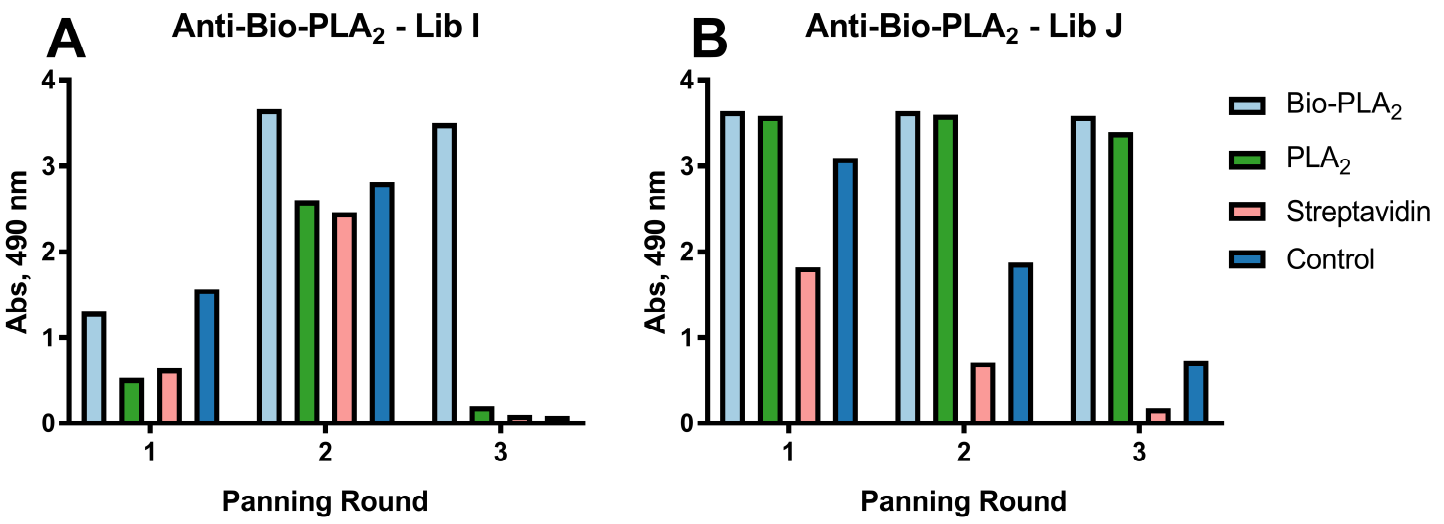

783

784 
Figure 7
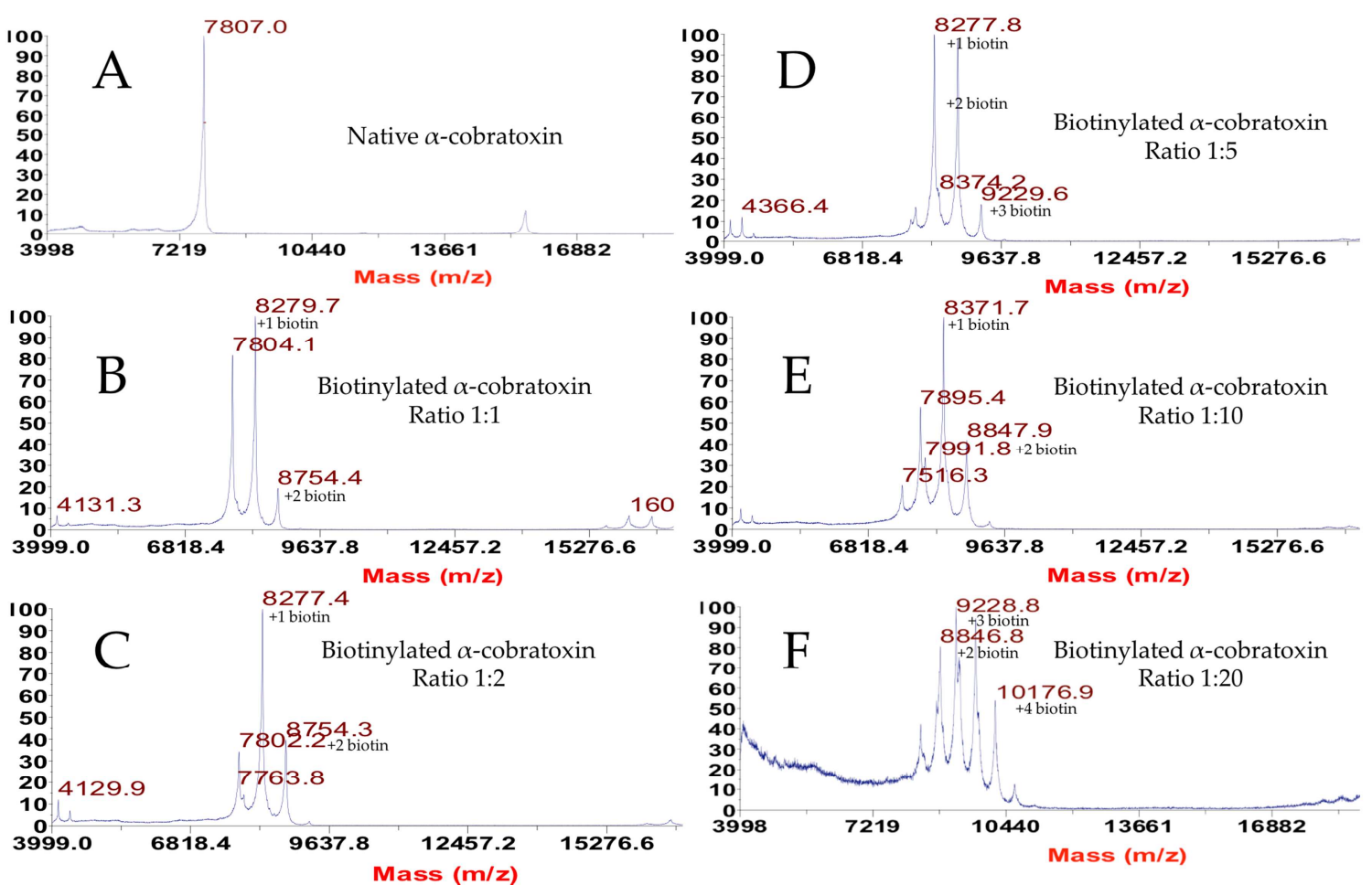
788 Figure 8
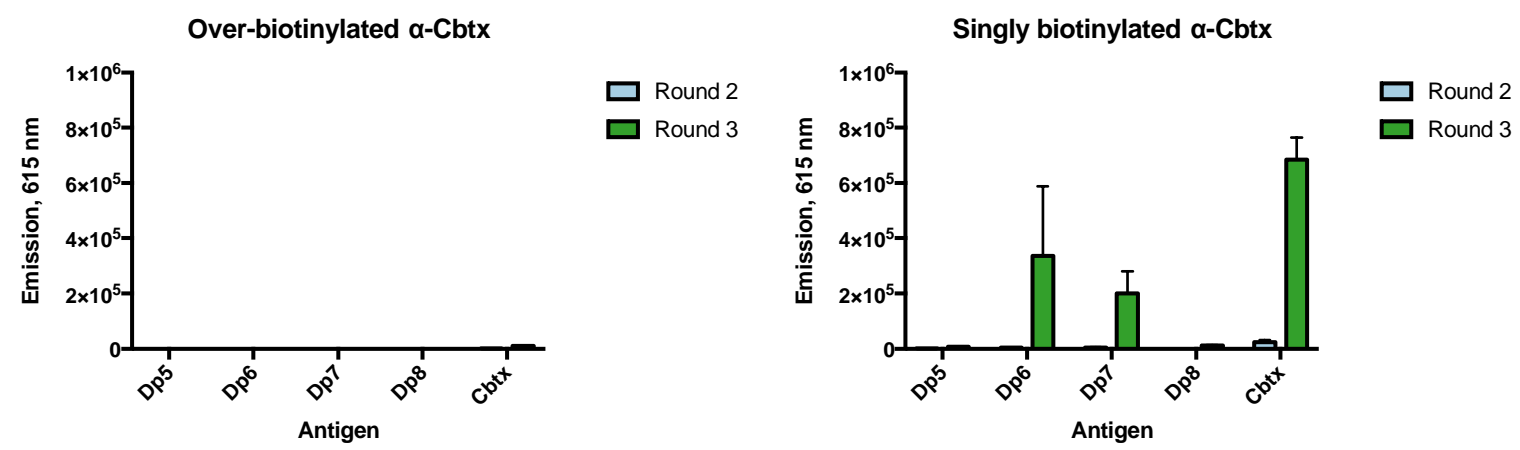
$791 \quad$ Figure 9
Toxin Biotin + aliphatic linker
Precipitation
$\mathrm{A} \bullet$
Toxin $\quad+?$ biotin + PEG-linker
$\longrightarrow \quad 8$
B ?
$\longrightarrow$
In solution

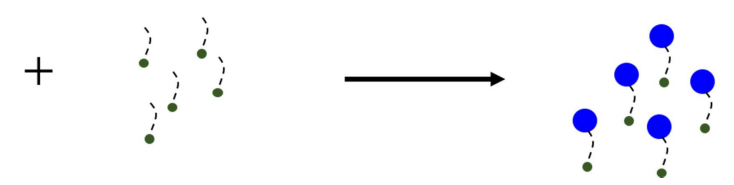

792

793 
794 Figure 10

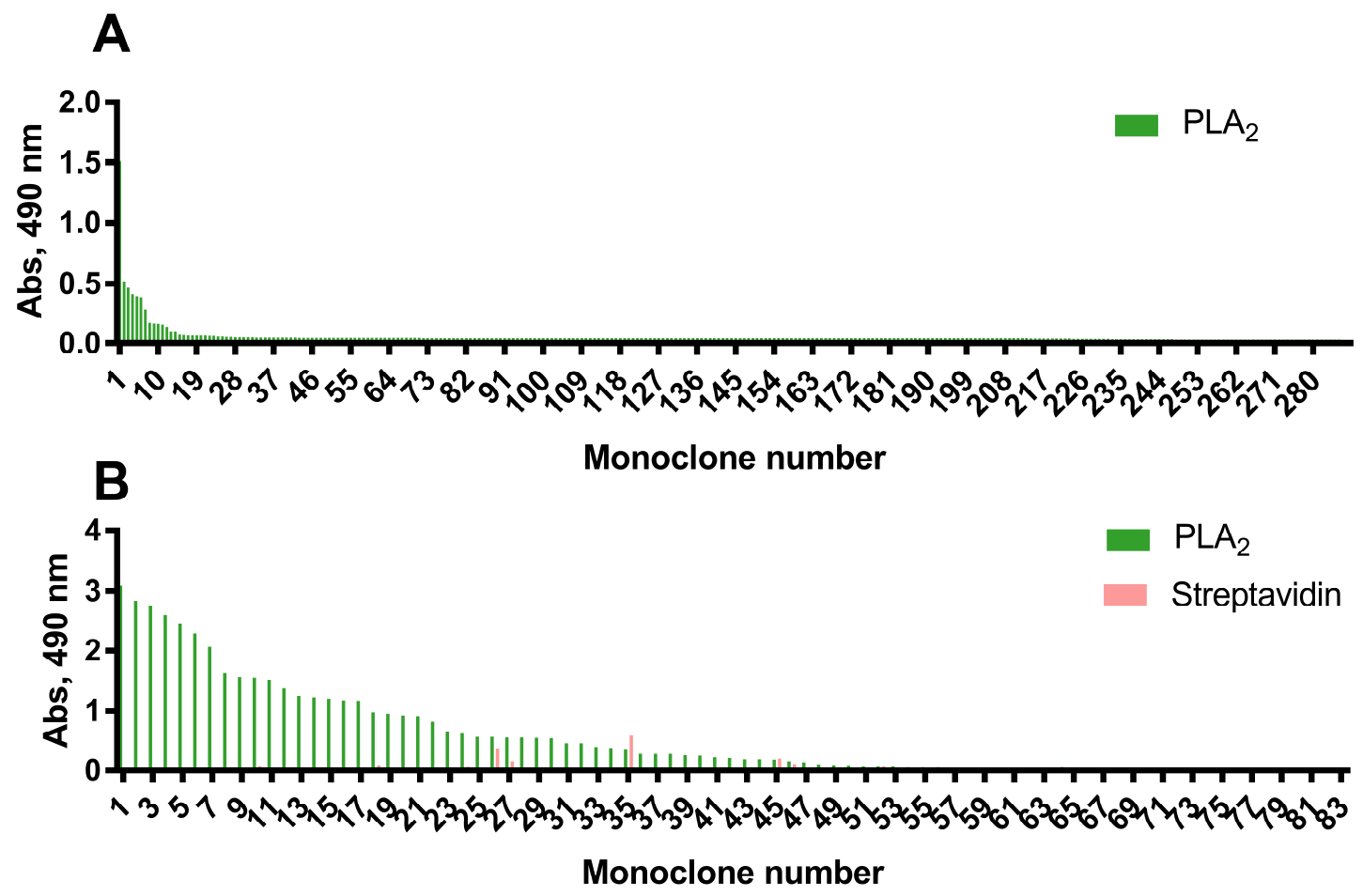

795 
$797 \quad$ Figure 11

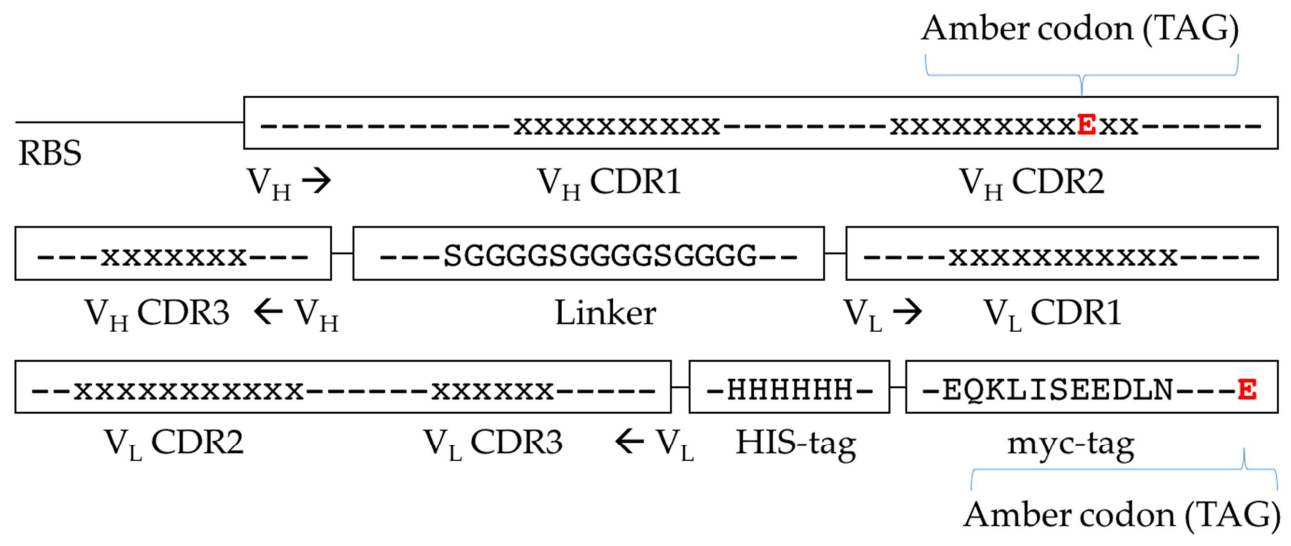

798 
There is no ethical issue to report, in connection with the manuscript.

Sincerely yours,

Brian Lohse

Brian Lohse, Ph.D.

Associate Professor

Chemical Biology \& Molecular Biology

CSO of EpiDiscoverY

Faculty of Health and Medical Sciences

Department of Drug Design and Pharmacology

University of Copenhagen

Jagtvej $160,3^{\text {rd }}$ floor, office C.327

2100 Copenhagen $\varnothing$.

Denmark

Office Phone: $(+45) 35336658$

Mobile Phone: $(+45) 93565431$

e-mail: bril@sund.ku.dk

Group Homepage: http://drug.ku.dk/research/molecular and cellular pharmacology/epidiscovery-group/ 